\title{
Original
}

\section{The Effect of Strontium on Osteoblastogenesis and Osteoclastogenesis in Dental Stem Cells-induced Epidermal Growth Factor at Molecular Level: In Vitro Study}

\author{
Hamid Hammad Enezei $^{1,2)}$, Ali Al Qabbani ${ }^{3)}$, Azlina Ahmad ${ }^{4)}$, Mohd Fadhli Khamis ${ }^{5)}$, Abdelkader Hassani ${ }^{(6)}$ and Hamad Ali Hamad \\ 1) Department of Oral and Maxillofacial Surgery, Collage of Dentistry, University of Anbar, Ramadi, Iraq \\ 2) Department of Oral and Maxillofacial Surgery, School of Dental Science, Universiti Sains Malaysia, Kelantan, Malaysia \\ 3) Department of Craniofacial Health Sciences, College of Dental Medicine, University of Sharjah, Sharjah, United Arab Emirates \\ 4) Department of Biochemistry, School of Dental Science, Universiti Sains Malaysia, Kelantan, Malaysia \\ ${ }^{5)}$ Department of Oral Biology and Forensic Dentistry Unit, School of Dental Science, Universiti Sains Malaysia, Kelantan, Malaysia \\ 6) Department of Chemical and Environmental Engineering, Faculty of Engineering, Universiti Putra Malaysia, Serdang, Malaysia \\ 7) Department of Biomedical Sciences, Faculty of Medicine and Health Sciences, Universiti Putra Malaysia, Serdang, Malaysia \\ (Accepted for publication, October 16, 2019)
}

\begin{abstract}
For a reconstructive surgeon in oral and maxillofacial surgery, repair of massive bone defects in craniofacial region and mandible caused by different types of trauma, extensive bone destruction by cancer or metabolic diseases is amongst one of the most difficult tasks to handle. The aim of this study was to assess the effectiveness and potential effect of incorporating Strontium (Sr) with locally delivered epidermal growth factor (EGF) on osteoclastogenesis and osteoblastogenesis gene expressions of dental stem cells (DSCs) in an in vitro study. Sr, EGF, and dental stem cells (DSCs) with all materials (reagents and drugs) were commercially purchased from companies. Viability test (cytotoxicity test) was carried out to determine compatibility and optimal concentrations of Sr scaffold and EGF in accordance with the protocol of the current study. DSCs were treated with three modalities of drugs base time points, control-0 concentration, DSCs treated with Sr only, DSCs treated with EGF only DSCs treated with Sr/ EGF. RNA from DSCs were extracted from all treated groups. RT-PCR was used to amplify the specific osteoblast/ osteoclast genes markers. Electrophoresis of the RT-PCR products was followed by gel image capturing. Significant enhanced osteoblast markers responsible for bone healing were observed in the DSCs group that were treated with $\mathrm{Sr} / \mathrm{EGF}$ as compared with the other studied group. This strategy seems to be a reliable new tool for bone tissue engineering by mean using bone graft material potentiates inducing high capacity of bone wound healing and could be effective strategy in reconstructive surgery when used in in vivo study used stem cellsbased therapy.
\end{abstract}

Key words: Osteoblastogenesis, Strontium, Epidermal growth factor, Dental stem cells, In vitro

\section{Introduction}

Successful surgical reconstruction protocol of massive bone defect using all previous types of bone grafts in Oral \& Maxillofacial Surgery, Craniofacial Surgery and Orthopaedic can pose serious problems in clinical surgery and still needs attention ${ }^{1}$. Repair process of bone defect depends on specific sequential interaction representing the scaffold of tissue matrix and stem cells or pluripotent cells with certain growth factors as protein within the standard local conditions or environment ${ }^{2-4)}$. Bone tissue is capable of complete regeneration without scarring. This property has enabled the development of bone tissue engineering $(\mathrm{BTE})^{5}$. Certain definition of bone wound healing in literature review with more simplified meaning of a complicated biological process that is initiated whenever tissue integrity is breached ${ }^{6}$. Wound healing involves cellular interactions to promote processes such as phagocytosis, chemotaxis, mitogenesis, angiogenesis, apoptosis and synthesis of numerous factors (e.g., collagen and extracellular matrix components) ${ }^{6}$. Strontium ( $\mathrm{Sr}$ ) is an element that has an approximate volume of distri-

Correspondence to: Dr. Mohd Fadhli Khamis, School of Dental Sciences, Health Campus, Universiti Sains Malaysia, 16150, Kota Bharu, Kelantan, Malaysia; Phone: +60179043307; E-mail: fadhli@usm.my bution of $11 / \mathrm{kg}$. The Sr binding capacity to human plasma proteins is low $(\sim 25 \%)$, but display high affinity for bone tissues. Studies showed that $\mathrm{Sr}$ elimination is performed by the kidneys and gastrointestinal tract, independent of time or dose ${ }^{7}$. The biological process of bone tissue repair is regulated through a large number of growth factors (GF) and cytokines through complicated intracellular events ${ }^{6}$. These factors provide signals that induces osteoprogenitors migration. Osteoprogenitor cells migration promotes the cellular differentiation, multiplication, tissue revascularization and extracellular matrix production. Effective regenerative process has been demonstrated after including growth factors, epidermal growth factor (EGF), bone morphogenetic proteins (BMPs), and fibroblastic growth factors (FGFs) in scaffolds seeded with stem cells ${ }^{8)}$. However, the use of these GF in clinical applications has been restricted due to their limited availability in terms of price, shelf life during storage and manipulation, and the short time in effectiveness after their application due to hydrolysis, neutralization, and degradation $^{7}$. Strontium is an osteoporotic anabolic drug currently prescribed to treat bone diseases in elderly patients (old-old) and postmenopausal pe$\operatorname{riod}^{9}$. Imbalance between the bone formation and resorption results in osteoporosis. The problem of such imbalance could be considered as the 
main causative factor behind the reduction or decrease in bone strength and increased bone fragility with the risk of fracture at the end ${ }^{10)}$. Sr is considered a unique dual effect of simultaneously promoting bone formation while inhibiting bone resorption ${ }^{10)}$, thereby improving bone strength. EGF plays an enhancer role on osteogenic differentiation of stem cells because it is capable of increasing extracellular matrix mineralization. EGF triggers endothelial cells, responsible for angiogenesis or vascularization. Grafting of massive bone defect or atrophic non-unions with mesenchymal stromal cells (MSCs) based graft is not a fruitful treatment protocol, in spite of autogenous type bone graft remain the gold standard graft ${ }^{11)}$. There are many shortcomings associated with allografts, xenografts and tissue-engineered based grafts. Some of the problems associated with these grafts include aging population, mortality, morbidity, insubstantial harvestable autographs, disease transmission and immunogenic response. Incorporated bone marrow mesenchymal stromal cells (BM-MSCs) in osteoconductive scaffolds with the help of BTE has not shown any promising clinical usage ${ }^{12}$. Using human BMMSCs, for the reconstruction of critical-sized bone defect (CSBD), have failed to fill large sized bone defects due to the insufficient amount of bone production ${ }^{13)}$. New dimensions for the development of biomaterials have been explored that have faster and better regeneration of bone with massive defect beside availability of graft amount and sufficient to reconstruct the defect in one session and no need secondary surgical intervention.

One of the most commonly used filling materials is the synthetic calcium phosphate $(\mathrm{CaP})$ ceramics. It is used as a substitute of autograft and allografts. Other features of synthetic $\mathrm{CaP}$ include resemblance with inorganic state of bone and osteoconduction. $\mathrm{CaP}$ based materials have shown very weak stimulation of bone cells, lower tendency of producing fragments and particles that may induce immune response. The induced pro-inflammatory immune response can be detrimental leading to the short survival of the implant ${ }^{14,15)}$. Bisphosphonates (BPs) are effective antiresorptive agents used to treat bone disorders including metabolic bone diseases and bone metastases. They have shown promising results as antiosteoporotic agent and used in tissue regeneration research. However, the single action of BPs in osteoclastogenesis and not in osteoblastogenesis impede it to be a drug of choice in bone tissue regeneration and looking for alternative drugs ${ }^{16)}$.

$\mathrm{Sr}$ is an anabolic drug with dual action that acts on both osteoblasts and osteoclasts. It is widely used as a medication for osteoporosis due to its role in the formation of new bone and osteolytic inhibition. Bone replacement material development in the form of a composite graft with anabolic effect is an important objective in Oral \& Maxillofacial Surgery, Craniofacial Surgery and Orthopedic Surgery. There is a dire need of developing BTE based therapeutic modalities for accelerated bone healing within a single surgical operation. So far, no other study is looking at the use of MSCs obtained from dental tissue like used in our design of the study DSCs incorporated into Sr loaded with EGF protein in controlled release of drug using fibrin glue (FG) as a natural delivery vehicle.

\section{Materials and Methods}

This research project was carried out and completed in at Craniofacial Science Laboratory, School of Dental Sciences, Health Campus, Universiti Sains Malaysia, Kelantan. Materials used in the cell culture are given in Table 1. All chemicals and reagents used in cell culturing were obtained from (Gibco, USA). Drugs, growth factors, reagent kits were prepared according to the supplier's protocol. Dulbecco's Modified Eagle Medium (DMEM) (high glucose $4.5 \mathrm{~g} / \mathrm{l}$ ) enriched with fetal bo-
Table 1. List of cell line, media, buffers, reagents, drugs, antibiotics and analytical kits were used in cell culture

\begin{tabular}{|c|c|}
\hline Supplier & Name \\
\hline Invitrogen, USA (GIBCO) & $\begin{array}{l}\text { Epidermal Growth Factor (EGF) } \\
\qquad 10 \mu \mathrm{g} / \mathrm{pk}\end{array}$ \\
\hline Sigma, St. Louis, MO & Strontium (Sr), Powder \\
\hline BioSUN Biotechnology, Malaysia & Primer Synthesis \\
\hline $\begin{array}{l}\text { (Cusabio Biotech Co., Ltd, } \\
\text { Wuhan, China) }\end{array}$ & $\begin{array}{l}\text { Human Epidermal Growth Factor } \\
\text { (EGF), enzyme-linked } \\
\text { immunosorbent assay (ELISA) } \\
\text { KIT,96T }\end{array}$ \\
\hline $\begin{array}{l}\text { AllCells, LLC Company, } \\
\text { Emeryville, CA, USA }\end{array}$ & Dental Stem Cells (DSCs) \\
\hline $\begin{array}{l}\text { Invitrogen, (GIBCO), Faraday } \\
\text { Ave, Carlsbad, CA, USA }\end{array}$ & $\begin{array}{l}\text { Dulbecco's modified Eagles medium } \\
\text { (DMEM) high glucose }(4.5 \mathrm{~g} / \mathrm{l})\end{array}$ \\
\hline $\begin{array}{l}\text { Invitrogen, (GIBCO), Faraday } \\
\text { Ave, Carlsbad, CA, USA }\end{array}$ & Fetal bovine serum (FBS) \\
\hline $\begin{array}{l}\text { Invitrogen, (GIBCO), Faraday } \\
\text { Ave, Carlsbad, CA, USA }\end{array}$ & $\begin{array}{c}\text { Dulbecco's PBS } \\
\text { (without } \mathrm{Ca}^{2+} \text { and } \mathrm{Mg}^{2+} \text { ) }\end{array}$ \\
\hline $\begin{array}{l}\text { Invitrogen, (GIBCO), Faraday } \\
\text { Ave, Carlsbad, CA, USA }\end{array}$ & Penicillin/streptomycin, liquid \\
\hline $\begin{array}{l}\text { Invitrogen, (GIBCO), Faraday } \\
\text { Ave, Carlsbad, CA, USA }\end{array}$ & $\begin{array}{c}\text { Triple }^{\mathrm{TM}} \text { Express Stable Trypsin } \\
\text { Replacement Enzyme without } \\
\text { Phenol Red }\end{array}$ \\
\hline $\begin{array}{c}\text { (Biophotometer, Eppendorf AG, } \\
\text { Hamburg,Germany) }\end{array}$ & Spectrophotometer \\
\hline $\begin{array}{l}\text { (Analytik Jena AG, Konrad-Zuse- } \\
\text { Strasse 1, } 07745 \text { Jena, Germany) }\end{array}$ & $\begin{array}{l}\text { innuPREP RNA Mini Kit-850-KS- } \\
\qquad 2040050\end{array}$ \\
\hline QIAGEN, USA & $\begin{array}{c}\text { one-step Reverse Transcriptase } \\
\text { Polymerase Chain Reaction RT-PCR } \\
\text { Kit }\end{array}$ \\
\hline $\begin{array}{c}\text { Baxter Healthcare Corporation, West- } \\
\text { lake Village, CA- } 91362 \\
\text { USA, US License No.140 }\end{array}$ & Tisseel Fibrin Sealant (FG) KIT \\
\hline Ajax Finechem Pty Ltd - Australia & Dimethyl Sulphoxide (DMSO) \\
\hline $\begin{array}{l}\text { Invitrogen Corporation, (San } \\
\text { Diego, California, USA) }\end{array}$ & PrestoBlue ${ }^{\circledR}$ Cell Viability Reagent \\
\hline
\end{tabular}

vine serum (FBS) 10\% was used to explant the DSCs.

\section{Viability and cytotoxicity test}

When using any chemical or physical material in tissue engineering, it is important to consider factors such as biocompatibility and minimal non-toxicity in order to promote cell migration, cellular differentiation, multiplication and cell adhesion without interference with other vital organs or living tissues (ISO/EN 10993-5) ${ }^{17}$. Determination of optimal concentrations of $\mathrm{Sr}$ and EGF by cytotoxicity analysis was done. Different concentrations of Sr extract treated-DMEM media were used in viability assays (1.0 mM, 2.0 mM, $4.0 \mathrm{mM}$, and $6.0 \mathrm{mM}$ ) with four different time intervals (day 1, 3, 7, 14) for incubation of the cells. Untreated media were used for the control group (Figs. 1 and 2).

\section{EGF-treated media}

To reconstitute the lyophilized EGF for working solution, sterile distilled water or RNase-free water was used and stored at $\leq-20^{\circ} \mathrm{C}$ after reconstitution. Concentration of EGF in each vial was $10 \mu \mathrm{g} / \mathrm{ml}$. When needed, $10.000 \mathrm{ng} / \mathrm{ml}$ volume per $1 \mathrm{ml}(1,000 \mu \mathrm{l})$ was obtained by adding $1 \mathrm{ml}$ distilled to each vial. According to the experimental protocol, different concentrations of EGF media were used (Figs. 1 and 2). 
Hamid Hammad Enezei et al.: Effect of Strontium and Epidermal Growth Factor in Bone Tissue Engineering
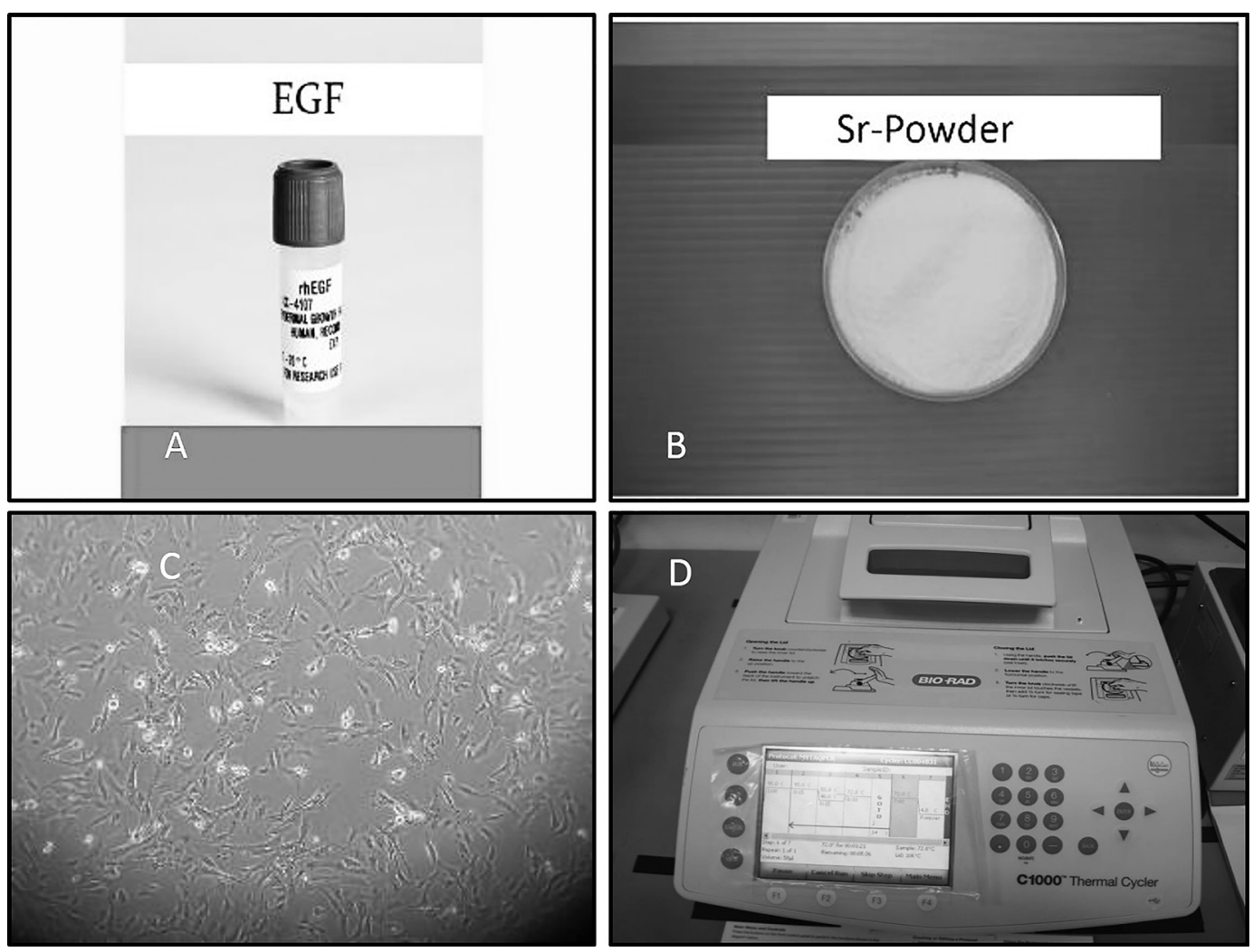

Figure 1. A, EGF in in lyophilized form was stored at $2^{\circ} \mathrm{C}$ to $8^{\circ} \mathrm{C}$, preferably desiccated. B, Sr powder. C, DSCs treated Sr- added EGF. D, PCR machine
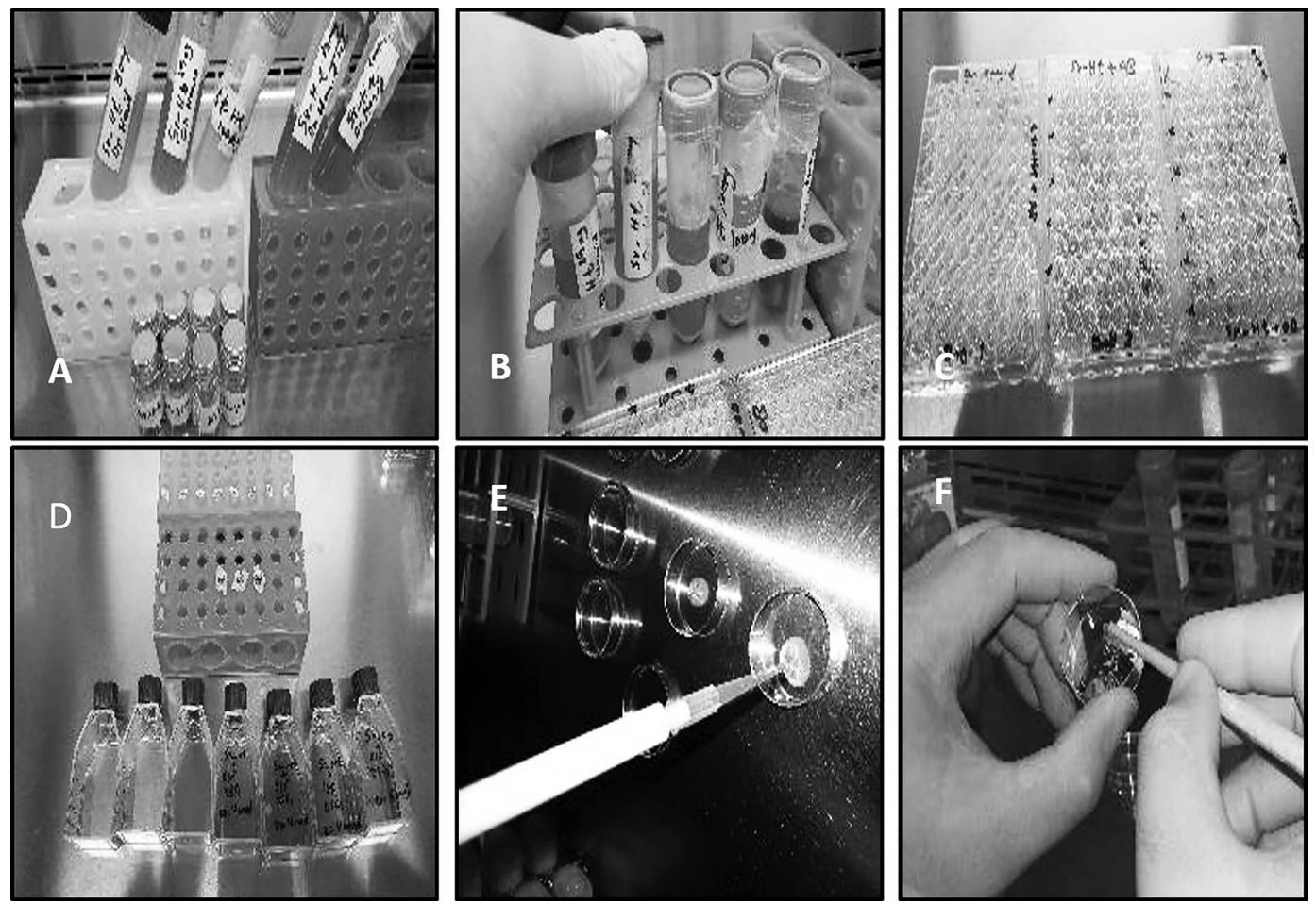

Figure 2. A, Sr powder loaded with $20 \mathrm{ml}$ solvent in $50 \mathrm{ml}$ centrifuge tube, B, the supernatant was filtered through a membrane $0.2 \mu \mathrm{m}, \mathrm{C}$, centrifugation of the extract after filtration process and cytotoxicity test using 96 well plate, D, pure extract was ready to make serial dilutions and used. Preparation with aliquots of EGF and stored at $\leq-20^{\circ} \mathrm{C}$, E, F, FG matrix carry EGF inside the prepared flack contain DSCs treated Sr powder. 


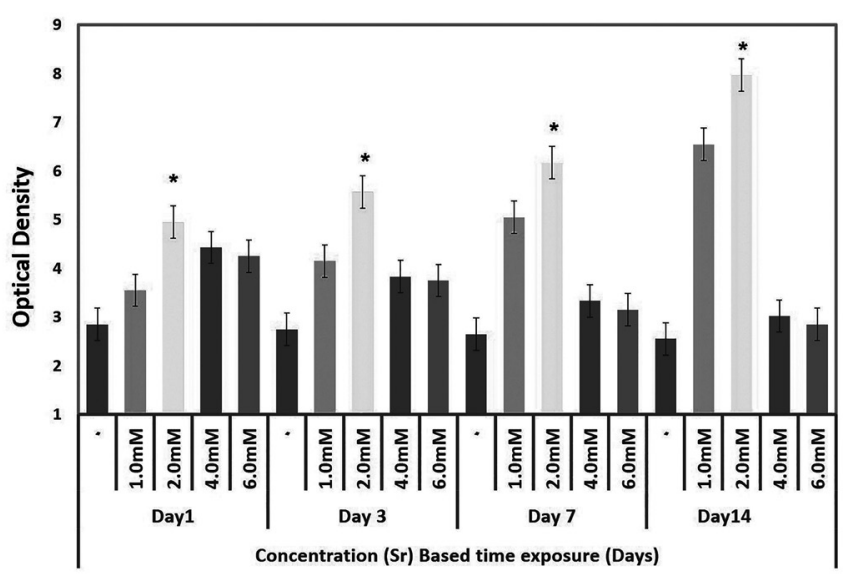

Figure 3. Cytotoxicity test of DSCs treated with different concentrations of $\mathrm{Sr}$, cytotoxic effect of $\mathrm{Sr}$ treatment increased significantly over time in culture and the most dramatic increase at the highest drug concentration $2.0 \mathrm{mM}$ of $\mathrm{Sr}$ $(\mathrm{P}<0.05) .0$ concentration of $\mathrm{Sr}$ did not show a significant change in control groups at all-time points. *, a significant difference when compared to other concentrations and control group (0), the experiment was repeated 3 times.

\section{Preparation of synthetic page purified-type primers}

Ten $\mu \mathrm{M}$ primer was prepared by mixing $5 \mu \mathrm{l}$ of $100 \mu \mathrm{M}$ primer with $45 \mu \mathrm{l}$ RNase-free water. From the prepared $10 \mu \mathrm{M}$ primer, $1.5 \mu \mathrm{l}$ was added to the PCR master mix. One step RT-PCR was carried out to osteoblastogenesis and osteoclastogenesis target gene bone formation markers like osteoprotegerin (OPG), collagen type 1 (CO1-1), Osteoblast enzymes, Alkaline phosphatase (ALP) and bone resorption marker receptor activator of nuclear factor kappa-B ligand (RANKL) according to the manufacturer's instructions. Specific primers i.e. human GAPDH (F): 5'-CAGAACATCATCCCTGCCTCT-3' (R) : 5'-GCTTGACAAAGTGGTCGTGAG-3 ${ }^{\text {18) }}$, human OPG (F): 5'-GCTTGAAACATAGGAGCTG -3' (R) :5'- GTTTACTTTGGTGCCAGG -3 ${ }^{\text {, }}$ ') , human RANKL (F):5'-CACTATTAATGCCACCGAC-3' (R) :5'- GGGTATGAGAACTTGGGATT- 3, ${ }^{18)}$, human Collagen Type-I (Col-1) (F) 5'GATGGATTCCAGTTC GAGTAT G -3' (R) :5' - GTTTGGGTTGCTTGTCTG TTTG -3,' ${ }^{19}$, human ALP (F): 5'-TGGAGCTTCAGAAGCTCAACACCA-3' (R): 5'-ATCTCGTTGTCTGAGTACCAGTCC-3'were used in the RT-PCR ${ }^{20)}$.

\section{Preparation of the extracts of $\mathrm{Sr}$ powder}

International standardized conditions (ISO/EN 10993-5) ${ }^{17)}$ were maintained during the preparation of $\mathrm{Sr}$ powder extract for indirect tests ${ }^{17)}$. In labeled tubes, $50 \mathrm{ml}$ samples were mixed with $20 \mathrm{ml}$ of DMEM solvent and were sealed with paraffin. A low rotational speed (50 rpm) shaking plate was used for the incubation of all the tubes for 7 days. After 7 days, tubes were filtered through $0.2 \mu \mathrm{m}$ filter membrane to obtain the supernatant in a $50 \mathrm{ml}$ tube. All the tubes were then centrifuged at 2,000 rpm for 4 minutes and sufficient amount of the supernatant was collected carefully (Figs. 1 and 2). Serial dilutions of the prepared pure extract were made using DMEM media.

\section{Cell culture and cytotoxicity assay}

DSCs were treated with different concentrations of $1.0 \mathrm{mM}, 2.0$ $\mathrm{mM}, 4.0 \mathrm{mM}$ and $6.0 \mathrm{mM} \mathrm{Sr}$ powder extract. After lysis, standardized number of cells were transferred into a $96-$ well plate and incubated in $5 \% \mathrm{CO}_{2}$ and $95 \%$ humid atmosphere at $37^{\circ} \mathrm{C}$. Untreated media with $0 \mathrm{Sr}$ concentration, was used for the control group. As per protocol, the via-

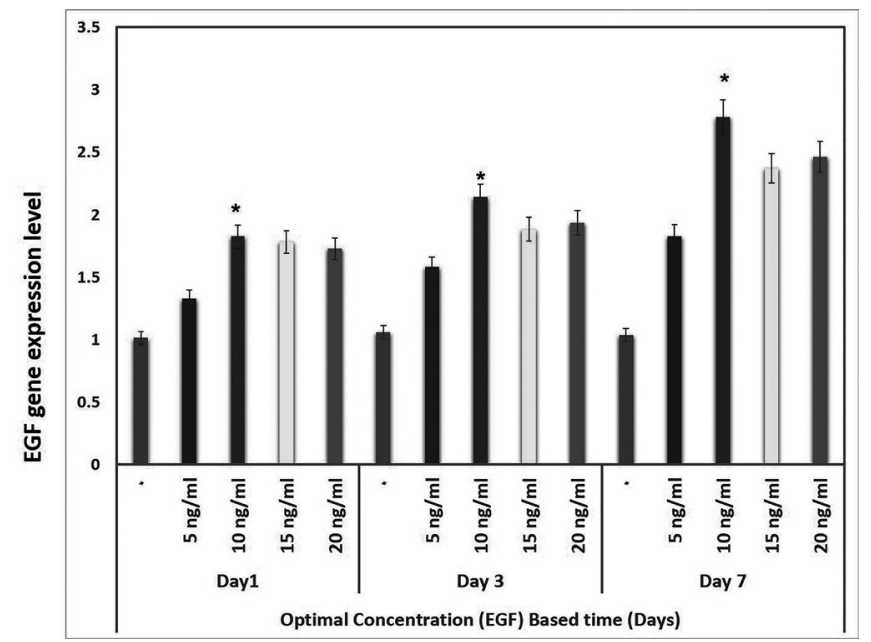

Figure 4. Optimizing EGF concentration by (proliferation assays using onestep-RT-PCR), $10 \mathrm{ng} / \mathrm{ml}$ was considered an optimal concentration treated on DSCs when compare it with other concentrations and $0(\mathrm{P}<0.05)$. The levels of EGF express on DSCs treated with EGF at different concentrations, $10 \mathrm{ng} / \mathrm{ml}$ showed the best result compared with $5 \mathrm{ng} / \mathrm{ml}$ and no significant difference can be seen between $15 \mathrm{ng} / \mathrm{ml}$ and $20 \mathrm{ng} / \mathrm{ml}((\mathrm{P}>0.05)$.

bility tests were carried out after incubation at different intervals i.e. day $1,3,7$, and 14 . Ten $\mu 1$ PrestoBlue ${ }^{\circledR}$ cell viability reagent $(\mathrm{PB})$ was added to each well and incubated according to the above-mentioned specifications for 2 hours. Samples were protected from light exposure and kept in dark. Absorbance of each well was read at 570 and $600 \mathrm{~nm}$ using enzyme-linked immunosorbent assay (ELISA) reader scan. In DSCs the induced regulated gene expression by EGF (at concentrations of 5, 10, 15 and $20 \mathrm{ng} / \mathrm{ml}$ ) was evaluated. After collection, DSCs passage 4 were cultured in $\mathrm{T}-25 \mathrm{~cm}^{3}$. After incubation, the EGF genes were amplified by RT-PCR. After electrophoresis of the PCR products, the bands were stained and images were obtained AlphaEaseFC ${ }^{\text {TM }}$ (Alpha Innotech, USA). Image J 1.46r software (National Institutes of Health, USA) was used for the analysis of the gel images. Untreated media was cultured with cells and considered as control group. Harvesting of cells was done on day 1, 3 and 7. InnuPREP RNA Mini Kit (Analytikjena, Germany) was used to isolate RNA from both treated and non-treated samples. The isolated RNA was stored at $-80^{\circ} \mathrm{C}$ (Figs. 1 and 2). Each experiment was triplicated.

\section{Preparation of fibrin glue (FG) matrix and measurement of EGF delivery}

Varying concentrations of fibrin glue (FB) were prepared according to the manufacturer's instructions in a heating water bath. Aprotinin solution was used after diluting it from 3,000 KIU/ml to $100 \mathrm{KIU} / \mathrm{ml}$. EGF-specific enzyme-linked immunosorbent assay (ELISA) kit was used to measure the potency and constant release of EGF from FG matrix $^{21)}$. To validate the analytical procedure and statistical analysis, the tests were run in triplicate (Fig. 2).

\section{Osteoblastogenesis and osteoclastogenesis gene expressions experiments}

Optimal concentrations of $\mathrm{Sr}$ and EGF were determined and three different modalities were used to expose DSCs to the Sr and EGF. The three modalities were $\mathrm{Sr}$ alone, EGF alone and $\mathrm{Sr}$-added EGF. Harvesting of cells were carried out on day 7, 14 and 21. Then RNA was isolated from the harvested cells using RNA Mini Kit (Analytikjena, Germany). Osteblastogenetic and osteoclastogenetic genes were amplified by RT-PCR (Fig. 2). 


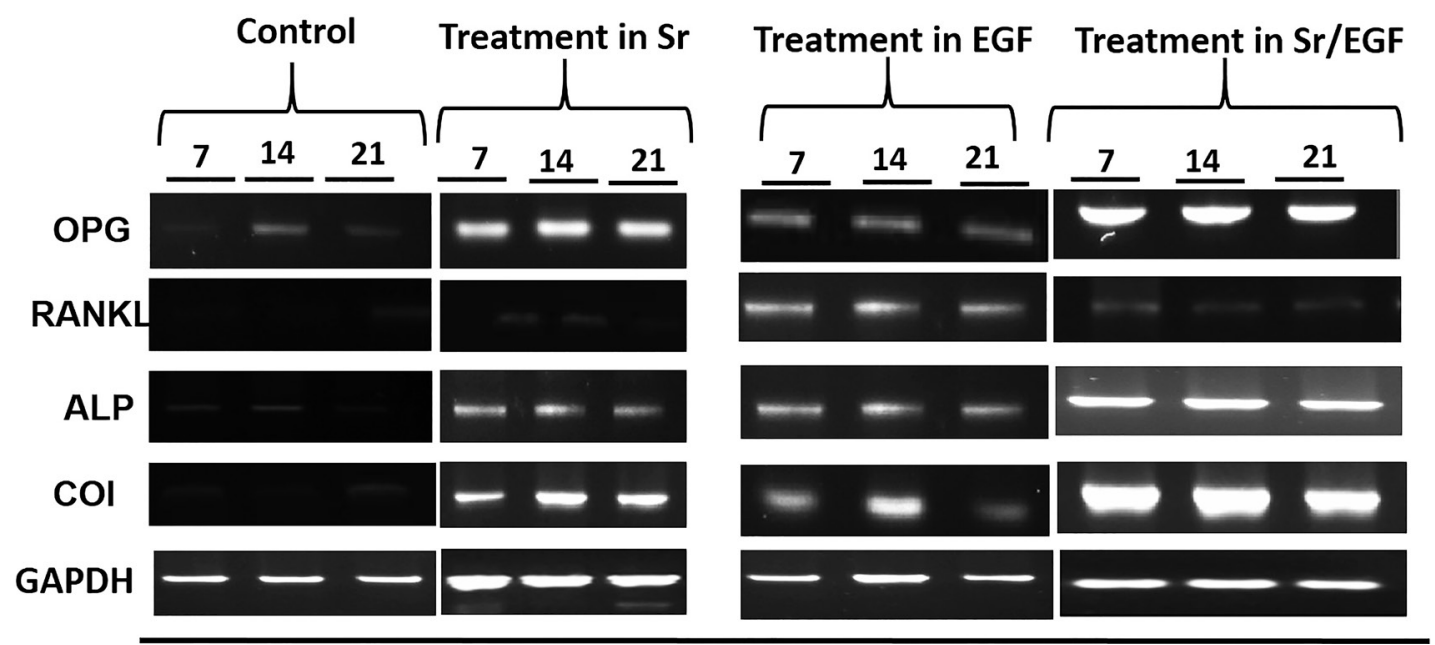

Figure 5. RT-PCR was performed on triplicate samples by using primers specific for bone formation/resorption markers of osteoblast differentiation phase from DSCs in response to treatment modalities used (Sr, EGF, and Sr-added EGF) after day 7, 14 and 21 from the culture.

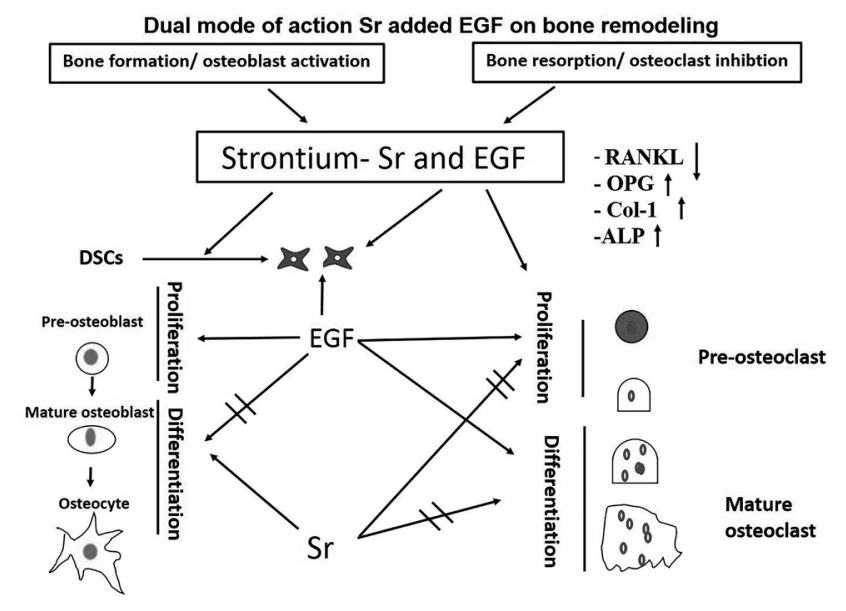

The role of the EGF in mediating anabolic actions on bone formation

Figure 6. A simplified schematic diagram when using Sr- added EGF to treated DSCs in our design and the intracellular signaling pathway (molecular), showing $\mathrm{Sr}$ action in different stages of the differentiation of DSCs into osteoblasts but mild inhibition of proliferation phase. While the effect of exogenous EGF may have the ability to enhance the proliferation phase of osteoblast but arrest osteoblastic differentiation in a preosteoblastic stage. On the other hand, Sr inhibits osteoclast maturation, while EGF enhancing of osteoclastogenesis. Increases the OPG level which decreases the RANKL expression on osteoblast and prevents the cross talk with RANK on osteoclasts.

\section{Statistical analysis}

Statistical software PASW ${ }^{\circledR}$ Statistics 20.0 (SPSS Inc, Chicago, IL, USA) was used for data analysis. One-way analysis of variance (ANOVA) was used to compare the cytotoxicity of varying concentrations of Sr treated DSCs. Post hoc test was used to test the optimal concentration with a $\mathrm{p}$ value of $<0.05$. Independent t-test was used to determine the optimal concentration of EGF.

For osteoblastogenesis and osteoclastogenesis gene expressions, the GAPDH-normalized band intensities of DSCs samples were compared with that the control. Data were collected by quantifying band intensity of GAPDH values divided by band intensity of DSCs values for each sample using Quantity One ${ }^{\circledR}$ 1-D analysis software (USA). Data were analyzed using Kruskal Wallis test. The p-values of less than 0.05 were considered statistically significant if less than 0.05 . Mann Whitney $U$ test followed with multiple comparison analysis was also employed when indicated.

\section{Cytotoxicity assay of Sr treated DSCs}

Signifiant proliferation of DSCs were observed at a concentration of $2.0 \mathrm{mM} \mathrm{Sr}$ treated media in comparison with other concentrations i.e. $1.0 \mathrm{mM}, 4.0 \mathrm{mM}$ and $6.0 \mathrm{mM}$ and control 0 concentration $(\mathrm{p}<0.05)$. Cells viability was $100 \%$ at $2.0 \mathrm{mM}$ (Fig. 3). Viability test of Sr powder at different concentrations was expressed as relative cell viability that is a percentage of the readings (or activities) in the absence of $\mathrm{Sr}$ drug. Non-treated media (control) were assigned a value of $100 \%$. No cell death was detected under light microscope for the optimal concentration group with high cell proliferation (positive biological cell activity) during the four-time points of DSCs differentiation in Sr treated media.

\section{Optimization assay of EGF treated DSCs at different concentrations}

The optimal concentration of EGF treated DSCs using RT-PCR was $10 \mathrm{ng} / \mathrm{ml}$ with a p value of $<0.05$ (Fig. 4), compared with other concentrations used in our experiment. Ten $\mathrm{ng} / \mathrm{ml}$ expressed higher EGF gene level among other concentrations.

Sr added EGF upregulated the osteoblastogenesis-related gene expression

Gene expressions of OPG, RANKL, ALP and COI-1 at mRNA level in three groups of treatment modalities was analyzed using RT-PCR. Our data showed that the normalized expressions of OPG, RANKL, ALP and COI-1 in the Sr- added EGF group in controlled release manner were $941.8 \pm 19.1 \%, 155.22 \pm 5.3 \%, 898.4 \pm 1.2 \%$, and $855.7 \pm$ $3.9 \%$ respectively, which were significantly higher than those of the Sr-only group (OPG, RANKL, ALP and COI-1) $396.33 \pm 23.4 \%, 130.34$ $\pm 7.5 \%, 320.2 \pm 3.8 \%$, and $370.4 \pm 6.2 \%$ respectively, and higher than those of the EGF-only group (OPG, RANKL, ALP and COI-1) $280.75 \pm$ $14.2 \%, 250.34 \pm 3.6 \%, 260.75 \pm 2.4 \%$, and $280.22 \pm 4.3 \%$ respectively, $\mathrm{P}<0.05$ for all). This suggests that the expression of osteoblastogenesis genes markers (OPG, ALP and COI-1) was increased in response to Sr-added EGF treatment group $(2.0 \mathrm{mM} / 10 \mathrm{ng} / \mathrm{ml})$ at mRNA levels and less expression was seen in osteoclastogenic cytokine RANKL. Interestingly, it has been shown that high expression of OPG can be seen in 
Sr-added EGF treatment group and less band intensity of RANKL seen in the same group of study. In addition, the expression levels of RANKL and OPG mRNA were evident due to decrease in RANKL mRNA expression and increase in OPG mRNA expression (Fig. 5).

\section{Discussion}

The volume of bone and amount of minerals with micro-architecture are under the control of both osteoblasts and osteoclasts action. The process of bone remodeling, bone resorption and bone wound healing mainly depend on the quality and quantity of the main bone cells which also considered osteoblasts, osteoclasts, and endothelial cells ${ }^{22)}$. Systemic and local factors control the mechanism of bone remodeling and bone healing followed by trauma, which tightly regulates the cellular migration, proliferation, differentiation, activity and apoptosis of both osteoblasts and osteoclasts. For osteoblastogenesis and osteoclastogenesis, different types of drugs and growth factors have been discovered and have been used widely by many researchers. Sufficient data is available showing advantages and disadvantages of each drug.

$\mathrm{Sr}$ is a selective anabolic drug which has dual action of bone resorption (inhibition) and bone formation. It can trigger each gene related to bone resorption/bone formation in crosstalk mechanism. This dual role tends to increase bone remodeling in addition to excellent bone regeneration with good quality when used $\mathrm{Sr}$ added EGF in controlled released manner by sophisticated this biomaterial in composite form like scaffold (Fig. 6).

Besides, the role of $\mathrm{Sr}$ in stimulating osteoblastic proliferation, it is well recognized that $\mathrm{Sr}$ induces the osteoblastic differentiation more than proliferation. Our results stressed that $\mathrm{Sr}$ has an enhancing effect only in DSCs differentiation but not in proliferation phase. As well as, it has an inhibitory effect on proliferation of DSCs that confirmed the gene expression at mRNA level. On the other hand, EGF enhanced the proliferation of DSCs but not differentiation phase. The evidence in our results was represented by bone forming/ bone resorption genes, with increased ALP, OPG, and COI-1 genes expression in the group treated with $\mathrm{Sr}$ added EGF as compared with other treatment modalities. These findings are consistent with that of $\mathrm{Wu}$ et al. ${ }^{23)}$ and $\mathrm{Li}$ et al. ${ }^{24)}$. They stressed that the Sr treatment inhibited the proliferation of rat BM-MSCs with no significant difference with and without added $\mathrm{Sr}$ to culture media $(\mathrm{P}>0.05)$. Subsequently, over the past decade, researches in bone field, have explored new insights in the regulation of bone remodeling. There is a growing evidence of the pivotal role of three major contributors i.e. RANK-RANKL-OPG ${ }^{22,25)}$. It is well known that RANKL induces the differentiation of pre-osteoclasts into mature osteoclasts. It is achieved by increasing the production of OPG. Interaction of RANKL on osteoblasts with the RANK present on the surface of the osteoclasts is also suppressed by the Sr. This results in hypo proliferation, differentiation and survival of the osteoclasts. EGF can induce preosteoblastic proliferation. It can also inhibit the differentiation of preosteoblasts into osteoblasts (Fig. 6). On the other hand, osteoblasts produce RANKL and OPG. Increased expression of RANKL and RANKL/OPG ratio have been observed in the bone tissues of patients with osteoporosis ${ }^{24)}$. For the evaluation of osteoclastogenesis, RANKL/OPG ratio is an important index interestingly, due to fracture susceptibility associated with high serum RANKL levels, and high OPG levels are correlated with low risk of fracture. OPG a specific marker for active osteoblasts was used as a key factor to analyze the osteoclast regulation. Expression of OPG was found to be increased in Sr-added EGF group when compared with other groups of treatment and 0 concentration (control) group. At the onset of the mineralization, the expression of OPG was increased that re- mained at high level continuously. It resulted in a lower ratio of RANKL/OPG in the mature osteoblasts ${ }^{26}$. From these changes it could be concluded that the osteoblasts originated from DSCs may have other different roles that maintains the balance of the bone remodeling. ALP and COI-1 genes are other markers of osteoblasts. Their expression was found to be significantly high showing the mineralization of bone. Mineralization was high in the Sr- added EGF group when compared to the EGF-only, and Sr-only groups $(\mathrm{P}<0.05)$. Sr effectively stimulates the formation of bone and inhibition of bone resorption simultaneously. Our findings showed significantly decreased bone resorption due to the less expression can be seen with RANKL gene as observed in the RT-PCR image electrophoresis findings in Sr- added EGF group compared with other modalities of treatment $(\mathrm{P}<0.05)$. These findings were in agreement with other published study that had also demonstrated the positive role of $\mathrm{Sr}$ on the osteoblastic differentiation into osteocytes ${ }^{27)}$. As mentioned above, EGF enhances the proliferation of DSCs but not differentiation phase, in our design, using EGF insures both proliferation and differentiation enhancing of the DSCs in reciprocal interaction. This results in the enhanced migration of osteoblasts into the tissues ${ }^{25)}$. Additionally, EGF can potently induce the formation of osteoclasts by regulating the expression of OPG and MCP-1 in osteoblasts ${ }^{27,28}$. Sr- added EGF may be a promising approach in bone tissue engineering strategy. Further in vivo and in vitro studies are needed using small animal as a screening sample before using large animal sample for the confirmation of these parameters and to evaluate the role of such biomaterials in a more complex system before resorting it clinically.

These findings indicate a role for new formula Sr- added EGF in controlled release manner may enhance our understanding of the mechanisms involved in bone tissue engineering in supporting bone regeneration during the process of skeletal repair in general, and, more specifically, when cell therapies are applied. We found that Sr potently replicates preosteoblasts and differentiates osteoblasts via expression of specific markers like ALP, OPG and COI-1. Promising results observed by combining Sr- added EGF open up a new strategy for modulating bone turnover, formation and resorption and as a scaffold for bone wound healing.

\section{Acknowledgment}

The authors acknowledge the University of Anbar, College of Dentistry and University of Science Malaysia (USM) for financial support by the USM Science Fund Grant No. (Short-term grant 304/ PPSG/61312104).

\section{Conflict of Interest}

The authors declare that there are no conflicts interest.

\section{References}

1. Enezei H, Azlina A, Mohd K, Roselinda A, Noor Hayati A and Samarendra S. Effects of local delivery of vascular endothelial growth factor on biological performance of the composite biomaterial used to accelerate bridging of critical-sized mandibular bone defect in rabbit model. JOMB 4: 93-99, 2015

2. Trejo-Iriarte G, Janeth B, Rocío E, Crisóforo M, Natalio H, Julia V and Luis M. Evaluation of bone regeneration in a critical size cortical bone defect in rat mandible using microCT and histological analysis. Arch Oral Biol 101: 165-171, 2019

3. Enezei H, Azlina A, Khamis M, Rahman R, Abdul Razak H, Mutum S and Samsudin R. Effect of local implantation of composite biomaterial loaded with vascular endothelial growth factor in healing of 
critical-sized mandibular defect-a pilot study. J Dent Oral Disord Ther 2: 1-5, 2014

4. Brennan Á, Renaud A, Amiaud J, Rojewski T, Schrezenmeier H, Heymann D, Trichet V and Layrolle P. Pre-clinical studies of bone regeneration with human bone marrow stromal cells and biphasic calcium phosphate. Stem Cell Res Ther 5: 114, 2014

5. Sun H, and Yang L. Calcium phosphate scaffolds combined with bone morphogenetic proteins or mesenchymal stem cells in bone tissue engineering. Chin Med J 128: 1121, 2015

6. Grazul-Bilska T, Johnson L, Bilski J, Redmer A, Reynolds P, Abdullah A and Abdullah M. Wound healing: the role of growth factors. Drugs Today (Barc) 39: 787-800, 2003

7. Martín-del-Campo M, Sampedro G, Flores-Cedillo L, Rosales-Ibañez R and Rojo L. Bone regeneration induced by strontium folate loaded biohybrid scaffolds. Molecules 24: 1660, 2019

8. George A and Veis A. Phosphorylated proteins and control over apatite nucleation, crystal growth, and inhibition. Chem Rev 108: 46704693, 2008

9. Bonnelye E, Chabadel A, Saltel F and Jurdic P. Dual effect of strontium ranelate: stimulation of osteoblast differentiation and inhibition of osteoclast formation and resorption in vitro. Bone 42: 129-138, 2008

10. Marie J, Felsenberg D and Brandi L. How strontium ranelate, via opposite effects on bone resorption and formation, prevents osteoporosis. Osteoporos Int 22: 1659-1667, 2011

11. van der Stok J, Koolen E, Jahr H, Kops N, Waarsing J, Weinans H and van der Jagt $\mathrm{O}$. Chondrogenically differentiated mesenchymal stromal cell pellets stimulate endochondral bone regeneration in critical-sized bone defects. Eur Cells Mater 27: 137-148, 2014

12. Geuze E, Prins J, Öner C, Van Der Helm J, Schuijff S, Martens C, Kruyt C, Alblas J and Dhert J. Luciferase labeling for multipotent stromal cell tracking in spinal fusion versus ectopic bone tissue engineering in mice and rats. Tissue Eng. Part A 16: 3343-3351, 2010

13. Chatterjea A, Meijer G, van Blitterswijk C and de Boer J. Clinical application of human mesenchymal stromal cells for bone tissue engineering. Stem Cells Int 2010: 1-12, 2010

14. Braux J, Velard F, Guillaume C, Jourdain L, Gangloff S, Jallot E, Nedelec M, Laquerrière P and Laurent-Maquin D. Strontium-substituted bioceramics particles: a new way to modulate MCP-1 and Gro- $\alpha$ production by human primary osteoblastic cells. Materials 9: 985-999, 2016

15. Grandjean-Laquerriere A, Laquerriere P, Laurent-Maquin D, Guenounou M and Phillips M. The effect of the physical characteristics of hydroxyapatite particles on human monocytes IL-18 production in vitro. Biomaterials 25: 5921-5927, 2004

16. Enezei H. Anti-resorptive agent coupled with IGF-1 supplementation modulates $\mathrm{Cx} 43 \mathrm{mRNA}$ expression in a maxillofacial bone cell line culture. Int Med J 25: 395-398, 2018

17. ISO/ EN. 10993-5. Biological evaluation of medical devices-Part 5: Tests for in vitro cytotoxicity. Geneva: International Organization for Standardization, 2009

18. Tat K, Pelletier P, Mineau F, Caron J and Martel-Pelletier J. Strontium ranelate inhibits key factors affecting bone remodeling in human osteoarthritic subchondral bone osteoblasts. Bone 49: 559-567, 2011

19. Sila-Asna M, Bunyaratvej A, Maeda S, Kitaguchi H and Bunyaratavej N. Osteoblast differentiation and bone formation gene expression in strontium-inducing bone marrow mesenchymal stem cell. Kobe J Med Sci 53: 25-35, 2007

20. Zhang X, Chang W, Lee P, Wang Y, Yang M, Li J and Yu X. Polymer-ceramic spiral structured scaffolds for bone tissue engineering: effect of hydroxyapatite composition on human fetal osteoblasts. PloS one 9: e85871, 2014

21. Enezei H, Ahmad A, Takeuchi K, Suzuki J, Khamis M, Razak N, Rahman R, Al Qabbani A, Abdulhameed E, Sugita Y and Maeda H. Osteoinductive activity of bone scaffold bioceramic companied with control release of VEGF protein treated dental stem cells as a new concept for bone regeneration: Part II. J Hard Tissue Biology 27: 69-78, 2018

22. Caudrillier A, Hurtel-Lemaire S, Wattel A, Cournarie F, Godin C, Petit L, Petit P, Terwilliger E, Kamel S, Brown M and Mentaverri R. Strontium ranelate decreases RANKL-induced osteoclastic differentiation in vitro: involvement of the calcium sensing receptor. Mol Pharmacol 28: 109, 2010

23. Wu X, Meng G, Wang S, Wu F, Huang W and Gu Z. Zn and Sr incorporated $64 \mathrm{~S}$ bioglasses: material characterization, in-vitro bioactivity and mesenchymal stem cell responses. Mat Sci Eng C 52: 242-250, 2015

24. Li Y, Li J, Zhu S, Luo E, Feng G, Chen Q and Hu J. Effects of strontium on proliferation and differentiation of rat bone marrow mesenchymal stem cells. Biochem Biophys Res Commun 24: 725-730, 2012

25. Delgado-Calle J, Sañudo C, Sumillera M, Garcés M and Riancho A. Expression of RANKL and OPG in primary osteoblasts. Rev Osteoporos Metab Miner 4: 133-139, 2012

26. Boyce F and Xing L. Functions of RANKL/RANK/OPG in bone modeling and remodeling. Arch Biochem Biophys 15: 139-146, 2008

27. Schneider R, Sibilia L and Erben G. The EGFR network in bone biology and pathology. Trends Endocrino Metab 20: 517-524, 2009

28. Nardone V, Fabbri S, Marini F, Zonefrati R, Galli G, Carossino A, Tanini A and Brandi L. Osteodifferentiation of human preadipocytes induced by strontium released from hydrogels. Int J Biomater 2012: 1-10, 2012 
J.Hard Tissue Biology Vol. 29(1): 1-8, 2020 